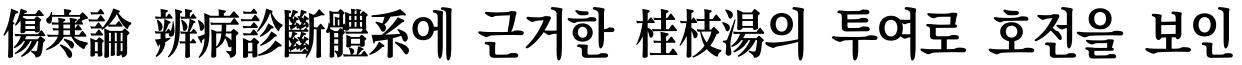 공황장애 환자 1례
}

\author{
노영범, 김지영* \\ 경기도 부천시 원미구 조마루로 105번길 34-13 노영범한의원
}

\section{A Case of Panic Disorder Patient Improved by Gyeji-tang(Guizhi-tang) Based on Shanghanlun Provision}

\author{
Young-Beum Roh, Ji-Young Kim* \\ Roh-Young-Beum Korean medical clinic, 105, Jomaru-ro, Wonmi-gu, Bucheon, Gyeonggi-do, Korea
}

\begin{abstract}
Objectives: The objective of this case report is to find a therapeutic effect of Gyeji-tang in panic disorder patients, based on Shanghanlun provision.

Methods: At patient's first visit, we had conducted a medical interview in order to diagnose the physical and mental symptoms of the patient. A questionnaire called BAI had been also used to measure the degree of anxiety in panic disorder. After all the diagnoses had been done, the patient was allowed to take $120 \mathrm{cc}$ of Gyeji-tang, three times a day for 25 weeks. 25 weeks later, we conducted a second medical interview to compare with the initial treatment and to evaluate whether his physical and mental symptoms had been decreased or not. Likewise, the patient was asked to fill out the BAI questionnaire to measure the decline of anxiety degree.

Results: Based on Shanghanlun provision, the patient with panic disorder due to overwork was diagnosed as Tai-yang-bing. Considering that the patient was having dyspnea, 15th provision of Gyeji-tang was selected and administered for 25 weeks. After 25 weeks, we could have observed that the main physical symptoms such as palpitation, dyspnea, stifling, headache, and fatigue were moderately improved. Moreover, the BAI score, which was evaluated to measaure the degree of anxiety, was also decreased from 49 points to the level of normal condition, 16 points.

Conclusions: A 44 year old male patient who suffered from panic disorder due to overwork was allowed to take 15 th provision Gyeji-tang for 25 weeks, based on Shanghanlun Provision. In results, the main physical symtpoms including dyspnea, palpitation, stifling, headache, and fatigue, and mental symptom such as extreme anxiety were all effectively improved.
\end{abstract}

$\overline{K e y ~ W o r d s ~}$ : Panic disorder, Gyeji-tang(Guizhi-tang), Diagnostic System based on Shanghanlun Provision

\section{서 론}

공황장애는 심한 불안발작과 이에 동반하는 다양 한 신체 증상들이 아무런 예고 없이 갑작스럽게 발생
하는 불안장애의 일종이다. 공황장애에서 발생하는 불안발작은 매우 심해서 거의 죽을 것 같은 공포심을 유발하는데 이외에도 흔히 심계항진, 온몸이 떨림, 호흡곤란, 흥통이나 가슴이 답답함, 어지럼증, 오심,

\footnotetext{
- Received : 28 January 2021

- Revised : 6 March 2021

- Accepted : 16 March 2021

- Correspondence to : 김지영

경기도 부천시 원미구 조마루로 105번길 34-13 노영범한의원

Tel : +82-32-666-7575, Fax : +82-303-3444-9168, E-mail : alsidbaba@hanmail.net
} 
발한, 질식감, 손발의 이상감각, 머리가 멍함, 쓰러질 것 같은 느낌이나 실제로 잠깐 실신하는 증상들이 나 타날 수 있다. ${ }^{1)}$

공황장애의 평생유병률은 인구의 $1.5-5 \%$ 로 보고 되고 있다. 양방적인 약물치료는 급성발작과 치료 초 기에는 주로 항불안 약물인 benzodiazepine 계통이 사용되고, 증상의 전반적 치료와 유지를 위해서 TCAs, SSRIs 등의 항우울제가 주로 쓰인다.

대개 양방적 치료에도 불구하고 만성적 주기적으 로 반복되고 환자 중 $10-20 \%$ 는 증상이 유지되면서 만성화한다고 한다. 만성화하면 많은 수에서 우울증 이 합병되고 자살의 우려도 있다. ${ }^{2)}$

한의학은 병명 위주가 아니고 증후 위주이기 때문 에 공황장애를 비롯한 신경증과 동일한 개념을 가진 독립된 질병명은 없으나 개개의 증상에 대해서는 논 하고 있다. 즉, 불면(不眠), 정충(怔忡), 경계(驚悸), 중기(中氣), 기울(氣鬱) 등과 같이 신경증에서 흔히 있을 수 있는 증상들이 마치 단독 질환과 같이 개별 적으로 취급되고 있으므로, 신경증에 대한 전체적인 개념을 실지증(失志證)이란 말로 정의하기도 하였 다. ${ }^{3)}$

특히 驚悸, 怔忡은 가슴이 躁動하고 잘 놀래며 마 음이 불안한 것을 자각하는 증후로, 현대의 공황장애 와 유사한 면이 있다. 東醫寶鑑·神·驚悸에서는 '驚 悸，因事有所大驚而成者，名曰心驚脆懾，病在心膽經' 이라 하여 心膽의 문제를 중요한 원인으로 인식하고

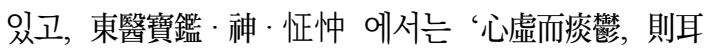
聞大聲，目擊異物，遇險臨危，觸事喪志，使人有惕惕之 狀, 是爲驚悸, 心虛而停水, 則胸中滲漉, 虛氣流動, 水酫 上升, 心火惡之, 心不自安, 使人有快快之狀, 是爲怔忡' 이라 하여 心虛로 인해 발생한다는 견해를 밝히고 있 다. ${ }^{2)}$

그동안 공황장애 환자에게 한의학적 치료를 적용 하여 호전시킨 증례는 수차례 있었다. 김) 등은 공황 장애 환자에게 怔忡, 心悸에 쓰이는 清心溫膽湯, 寧神 歸脾湯, 四物安神湯의 한약과 한의학적 정신요법을
통해 증상을 완화 시킨 케이스를 보고하였고, 서 ${ }^{5)}$ 등 은 공황장애 환자에게 桂枝加龍骨牡螗湯Ex제를 주치 료 약물로 투여하여 제반 증상들이 완화되는 결과를 보고하였으며, 놓ํ응은 공황장애 환자 102 명에게 영계감조탕을 투여한 결과 공황발작 및 제반 증상이 호전된 결과를 보고하였다. 하지만 계지탕(桂枝湯)을 주치료 수단으로 사용한 증례의 보고는 없었다.

본 증례에서는 44세 남성으로 심계항진, 흥민, 기 역(氣逆)을 특징적인 주증상으로 호소하는 공황장애 환자에게 약 25 주간 상한론(傷寒論) 15 번 조문에 근 거하여 계지탕(桂枝湯)을 투여한 결과 호전된 사례가 있어 보고하는 바이다.

\section{증 례}

\section{1. 성명, 성별 및 연령 \\ 채 $\mathrm{OO}$ (남자/44세)}

\section{2. 주소증}

1) Panic attack related symptoms : 심계항진, 가 슴답답함, 기역(氣逆), 호흡곤란, 어지럼증

2) Anxiety

3) 피로 두항강통(頭項强痛)

\section{3. 발병일}

내원일로부터 약 20년 전

\section{4. 과거력}

1) 진주종성 중이염; 약 24년 전

2) 2000년 panic disorder 진단받고 약물치료 후 중단

2017년 2019년 공황발작이 발생할 때마다 정 신건강의학과에서 SSRIs 계통 약물 처방 받아 2 주간 복용하고 증상 완화 후 중단하는 것을 반복하며 지내옴 


\section{5. 가족력}

별무

\section{6. 사회력}

1) 흡연: 1 갑/1일

2) 음주: 3 4회/주, 폭음

3) 직업: 신문기자

\section{7. 사진 초진 소견}

1) 망진(望診)

면황(面黄), $172 \mathrm{~cm}, 65 \mathrm{~kg}$ 의 다부진 체격

2) 문진(聞診)

특이 사항 없음

3) 문진(問診)

(1) 식욕 : 양호

(2) 소화 : 양호

(3) 대변 : 1일 2회, 무른 변

(4) 소변 : 7 8회, 시원하지 않다

(5) 구갈(口渴) : 보통

(6) 한출(汗出) : 보통

(7) 한열(寒熱) : 열이 확 달아오를 때가 있다.

(8) 수면(睡眠) : 비교적 양호, 불안할 때 잠이 오 지 않음

\section{8. 현병력}

상기 44세 남환은 2000년경 신문기자로 처음 사회 생활을 시작하면서 과로, 스트레스가 쌓이고 과음, 수면부족 상태에서 신문기사를 작성하는 도중 갑자 기 심장이 마비되는 듯한 공포감과 함께 심계항진, 질식감, 기역(氣逆), 어지럼증을 동반한 panic attack 이 최초로 발생하여 양방병원에서 일주일 입원치료 하고 퇴원 후 수시로 상기 증상이 발하여 local 정신 건강의학과 의원에서 공황장애 진단 하에 약물치료 를 해오다 치료를 중단 후 2017년경 다시 증상이 심 해져 약물치료 받아오던 환자로 최근 10 일 전 심한 불안과 가슴두근거림, 기역(氣逆)을 느껴 이에 대한
한의치료 위해 20OO년 O월 OO부터 OO한의원에 내원하였다.

\section{9. 임상적 진단}

1) Panic disorder

2) 상한론(傷寒論) 태양병(太陽病) 15조문(條文)

\section{0. 치료기간}

20OO년 O월 OO일 20OO년 O월 OO일

(총 175일, 25주, 12회)

\section{1. 치료 방법}

1) 한약치료

계지탕을 1 일 3 회, 1 회 $120 \mathrm{cc}$ 씩 복용하도록 하였 다. 계지 $9 \mathrm{~g}$ 작약 $9 \mathrm{~g}$ 감초 $6 \mathrm{~g}$ 생강 $9 \mathrm{~g}$ 대조 $8 \mathrm{~g}$ 을 1 첩 분량으로 하여 한 번에 15 첩 분량의 한약을 탕전 하였다. 물 $6000 \mathrm{cc}$ 를 넣고 물이 끓는 시간으로부터 1 시간 50 분 탕전 한 후 최종적으로 $5400 \mathrm{cc}$ 의 한약을 얻었다. 이를 1 팩에 $120 \mathrm{cc}$ 씩 45 팩, 15 일 분으로 나 누었다. 한약재는 대영제약에서 구입한 것을 사용하 였다. 탕전법은 Table 1과 같다.

Table 1. Composition and Administration of GyeJi-tang (Guizhi-tang)

\begin{tabular}{cc}
\hline Herbal name & Daily dose $(\mathrm{g})$ \\
\hline Cinnamormi Ramulus & 9 \\
Paeoniae Radix & 9 \\
\hline Zizyphi Fructus & 8 \\
\hline Zingiberis Rhizoma Recens & 9 \\
\hline Glycyrrhizae Radix & 6 \\
\hline Driod
\end{tabular}

Dried herbs above were decocted in boiled water. 120cc tid.

\section{2. 심리상태 자가 설문검사}

1) Beck 불안 척도 (Beck Anxiety Inventory :BAI) ${ }^{7)}$

공황장애의 주증상인 불안을 측정하기 위해 $\mathrm{BAI}$ 를 평가도구로 사용하였다. 총 21 문항으로 구성되어 
있으며 각 문항에서 1 주 동안 개인이 경험한 두근거 림, 현기증, 초조함, 두려움 등 불안의 인지적, 정서 적, 신체적 영역을 포함하는 여러 가지 불안 증상의 정도를 4 개의 문장 중에서 선택하도록 되어 있다. 각 항목 당 전혀 느끼지 않았다(0점), 조금 느꼈다(1점), 상당히 느꼈다(2점), 심하게 느꼈다(3점)으로 표시하 게 하여 각 문항의 점수를 합산하여 총점을 구하였 다. 증상 심각도의 등급은 $\mathrm{BAI}$ 총 점수에 의해 각각 22점 26점(불안상태), 27점 31점(심한 불안상태), 32점 이상(극심한 불안상태)으로 분류하였다.

\section{3. 치료경과}

\section{1) 시간에 따른 증상 변화양상}

(1) 2 주

근무할 때 이유 없이 수시로 불안이 왔다. 가슴이 답답했다. 가슴이 마구 뛰고 기가 위로 솟구치는 듯 한 느낌은 조금 줄어들었다. 피로감이 조금 줄었다.

1주일에 2 3번은 새벽 2시경에 잠이 들어 새벽 3 4시에 잠이 깬다. 한두 시간 동안 잠을 못 이루고 아침 5 시에 일어난다.

(2) 4 주

근무 도중 수시로 찾아오는 불안의 횟수가 줄었다. 과도한 업무를 마친 후, 퇴근 후 음주를 하면 가슴 이 답답해지면서 공황발작이 일어날까봐 불안하다.

가슴두근거림, 기가 위로 솟구치는 느낌이 조금 줄 었다.

어지럼증과 두통, 머리가 맑지 않은 느낌이 많이 줄었다.

\section{(3) 6 주}

불안의 강도, 심계항진, 기가 위로 솟구치는 느낌 이 확연하게 줄었다

퇴근 후 가슴답답함이 줄었다

두통과 뒷목의 뻣뻣함, 피로감이 중간정도 감소했다. 불안으로 새벽에 깨어나는 횟수가 줄었다(주3회/주
1회)

\section{(4) 8 주}

업무상 스트레스를 크게 받은 후 심계항진, 가슴답 답함, 호흡곤란이 두 차례 있었다. 강도는 예전보다 약해졌다. 뒷목이 굳어지고 머리가 맑지 않았다. 어 지럼증은 없었다. 발표할 기회가 있어서 긴장하고 미 리 걱정을 많이 했다. 공황발작으로까지 이어지지는 않았다. 음주 후 가슴이 답답한 것은 약간 좋아졌다.

스트레스를 많이 받아서 잠을 잘 못 잤다. (주2회) 새벽에 깨어나면 왼쪽 대퇴부에서 무릎까지 다리에 순환이 안되는 듯한 불편감이 들어서 다시 잠을 자기 힘들다.

(5) 10 주

예기불안이 거의 없었다.

심계항진, 가슴답답함, 기가 위로 솟구치는 느낌은 거의 없었다.

두통, 뒷목의 뻣뻣함, 어지럼증은 없었다.

피로감이 약간 있었고 찬 공기에 닿은 후 코막힘 이 있었다.

(6) 14주

업무가 많아서 피로감이 있었으나 강도는 줄었다. 과로 후 가슴두근거림, 답답함이 처음보다는 개선되 었지만 있었다. 호흡곤란, 어지럼증, 기가 위로 솟구 치는 느낌은 없었다. 수면상태는 조금 개선되었다.

전보다는 깊이 자고 새벽에 깨어나는 횟수가 줄었 다.(주1회)

온도 변화에 민감해서 찬공기에 닿으면 코가 막히 고 재채기가 난다. 예전보다 마음이 많이 편안해졌고 불안의 상황이 오면 차근차근 생각해보게 되었다.

(7) 16 주

가슴두근거림, 가슴답답함, 호흡곤란이 거의 나타 나지 않았다. 
머리가 많이 맑아졌고 어지럼증은 없다.

피로감과 뒷목이 뻣뻣한 것이 느껴지지 않았다.

과로 후 휴식을 취하려 하고 음주 횟수와 량(주

3 4회에서 주1 2회)을 줄이고 있다.

(8) 18 주

가슴두근거림, 가슴 답답함, 호흡곤란 증상이 10 에 서 2 3으로 줄었다.

예기불안이 나타나지 않았고 불안이 중등도 감소 했다.

피로감이 많이 개선되었고 머리가 맑지 않은 것도 많이 개선됐다.

(9) 20 주 후

공황장애의 증상들이 나타나지 않았다.

가슴두근거림, 기역(氣逆)은 없었고 가슴답답함이 조금 남아 있다.

과로 후 쉬려 하고, 음주를 줄여나가고 있다.
수면의 질이 개선되었다. 예전에는 주 2 3회 깼었 는데 2 주 동안 1 번만 깨고 비교적 잘 잤다.

(10) 22 주

가슴두근거림, 가슴답답함, 호흡곤란, 기역이 없었 다.

예기불안이 없었다.

피로가 많이 개선되었고 두통과 머리가 맑지 않은 느낌이 사라졌다.

(11) 25 주

가슴두근거림, 가슴답답함, 호흡곤란, 기역(氣逆)이 없었다.

예기불안이 없었다.

피로가 많이 개선되었고 머리가 맑지 않은 느낌이 사라졌다.

새벽에 깨어나는 횟수가 줄었다(주1회) (Table 2)

Table 2. Change of Treatment and Symptoms

\begin{tabular}{|c|c|c|c|c|c|c|}
\hline \multirow{2}{*}{ Weak } & \multirow{2}{*}{ Herbal Medicines } & \multicolumn{4}{|c|}{ Symptoms } & \multirow{2}{*}{ Other Symptoms } \\
\hline & & Palpitation/ & Dyspnea & Anxiety & Fatigue/Headache & \\
\hline & & Chest tightness & & & Neckstiffness & \\
\hline 2nd & Gyeji-tang & $+++/+++$ & ++ & ++ & $+++/+++$ & Sleeplessness \\
\hline 4 th & Gyeji-tang & $++/+1+$ & ++ & ++ & $+1+/++$ & \\
\hline 6 th & Gyeji-tang & $+/+$ & + & + & $++/+$ & \\
\hline 8 th & Gyeji-tang & $++/+1+$ & ++ & ++ & $++/+$ & Sleeplessness \\
\hline 10 th & Gyeji-tang & $+/++$ & + & + & $+/+$ & Sneeze \\
\hline 14 th & Gyeji-tang & $+/++$ & - & + & $+/+$ & Sneeze Nasal stuffiness \\
\hline 16 th & Gyeji-tang & $+/+$ & - & - & $+/-$ & \\
\hline 18th & Gyeji-tang & $+/+$ & - & - & $-/-$ & \\
\hline 20 th & Gyeji-tang & $-/+$ & - & - & $-/-$ & \\
\hline 22 th & Gyeji-tang & $-/-$ & - & - & $-/-$ & \\
\hline 25 th & Gyeji-tang & $-/-$ & - & - & $-/-$ & \\
\hline
\end{tabular}

Table 3. Changes of BAl Score

\begin{tabular}{cccc}
\hline & First Medical Examination & 6th & 25 th \\
\hline Score & 49 & 23 & 16 \\
\hline
\end{tabular}


2) 치료 전후 자가 설문 검사 상의 변화 (Table 3)

\section{고 찰}

공황장애는 특별한 이유 없이 예상치 못하게 나타 나는 극단적인 불안 증상, 즉 공황발작(panic attack) 이 주요한 특징으로서, 예기불안, 회피 행동 등을 함 께 보임과 동시에 심계항진, 호흡곤란, 식은 땀, 전 율, 숨이 막히는 느낌, 질식감, 가슴 답답함, 죽음에 대한 두려움 등 신체적 또는 인지적 증상 13 가지 중 적어도 4 가지 이상의 증상을 동반하는 것을 말한다. ${ }^{8}$

공황장애는 DSM-피에서 처음으로 불안신경증의 일부에서 독립되었으며 광장공포증을 동반하는 공황 장애와, 동반하지 않는 공황장애로 나뉘었다. 2013년 개정된 DSM-5에서는 공황장애와 광장공포증이 별 개의 질환으로 분리되었으며, 공황 발작(panic attack) 이 모든 DSM진단명에 동반될 수 있고, 예측/비예측 (expected/unexpected) 두 가지 유형으로 단순화 되 었다.9)

공황장애는 불안장애의 한 범주로 인식되고 있는 데, 한의학에서는 불안장애에 대해 경계(驚悸), 정충 (怔忡), 공경(恐驚), 초려(焦慮) 등의 범주에서 다루고 있다. ${ }^{10)}$

한편 상한론(傷寒論) 처방으로 공황장애를 치료한 연구가 활발하게 이루어지고 있다. $5,6,11)$

최근 상한론(傷寒論) 연구의 동향을 보면 다른 의 학서적과 주석가들의 이론체계로 상한론(傷寒論)을 해석하는 것을 배제하고 상한론(傷寒論)이 저술된 당 시의 서술구조에 기초하여 상한론(傷寒論)이 가진 자 체적인 진단체계를 설정하고 이를 검증하는 방향으 로 진행되고 있다. ${ }^{12,13)}$

변병진단체계(辨病診斷體系)란 이 ${ }^{13)}$ 등이 처음으로 제안한 것으로 기존의 상한론 연구에서 조문을 단순 히 환자의 몸에서 나타나는 증상의 나열로 해석한 것 에 반해, 조문을 질병과 관련이 있는 증상에 대한 원 인을 기술한 것으로 이해할 수 있음을 밝혔다. 기존
의 임상에서 환자가 현재 호소하는 주소증에 집중하 여 진단을 내리는 것에 반해, 변병진단체계(辨病診斷 體系)는 환자의 병력을 청취하는 과정을 통해 현재 주소증이 발생하게 된 원인, 또는 주소증을 발병하게 한 선행조건이 되는 증상을 확인하여 진단한다. 주소 증를 일으킨 원인과, 질병을 않고 있는 사람의 몸에 서 나타나는 병리적인 변화를 관찰하여 태양병(太陽 病), 양명병(陽明病), 소양병(少陽病), 태음병(太陰病), 소음병(少陰病), 궐음병(厥陰病) 6가지 형식(패턴)으로 구분하였는데 이를 육경 제강(六經 提絃)이라 한다.

진단의 첫 번째 단계는 육경 제강(六經 提網)을 선 정하는 것이고, 제강(六經 提綱)을 선정한 후에는 제 강(提網)의 아래에 수직으로 배속되어있는 하위개념 인 조문(條文)을 선정한다.

본 증례 보고는 공황장애 환자를 상한론 변병진단 체계(傷寒論 辨病診斷體系)에 근거하여 태양병(太陽 病)으로 분류하고 15 조문(條文), 태양병, 하지후, 기 기상충자, 가여계지탕.(大陽病, 下之後, 其氣上衝者, 可 與桂支湯)을 선정하여 계지탕(桂枝湯)을 처방하였다.

본 증례 보고의 환자는 심계항진, 가슴답답함, 기 역(氣逆), 호흡곤란, 어지럼증 등 공황장애의 증상을 주소로 내원하였다. 주소를 일으킨 원인과 선행조건 이 되는 증상을 찾아내기 위해 병력을 청취하였다.

환자는 대학 졸업 후 25 세 때 첫 사회생활을 시작 하였다. 신문기자로 신문사에 입사 후 과도한 업무에 시달렸다. 취재를 위해 장소를 가리지 않고 몸으로 뛰어야 했고 기사작성을 위해 밤낮 구분 없이 시간에 쫓기며 늘 긴장된 상태로 생활하였다. 야근과 잦은 회식으로 수면부족과 과음이 겹치면서 만성피로에 시달렸다. 신문기사를 작성하는 도중 심장마비가 오 는 듯한 공포를 느꼈고 심계항진과 호흡곤란, 기가 위로 솟구치는 듯한 증상이 나타나 응급실을 경유하 여 병원에 1 주일 입원한 후 퇴원하였다. 퇴원 후 곧 바로 공황발작이 수시로 일어나 local 정신건강의학 과 의원에서 공황장애로 진단받고 약물치료를 받았 다. 본 증례의 환자에게 주소가 온 원인은 몸을 무리 
하게 쓰고 과잉된 활동을 한 것으로(태양지위병 太陽 之爲病) 무리할 때마다(맥부 脈浮) 머리가 아프고 뒷 목이 뻣뻣하고(두항강통 頭項强通), 외부의 찬 공기에 닿으면 코가 막히고 재채기를 하는 등 온도에 민감해 지는 증상(이오한 而惡寒)이 있었다. 이는 태양병(太 陽病)의 제강과 일치한다고 보아 태양병(太陽病)으로 분류하였다. ${ }^{14,15)}$

과잉행위의 심리적 동기는 누구보다 잘해야 한다 는 욕구 때문이다. 누구보다 잘하고 싶은 욕구가 발 동하면 경쟁심과 승부욕이 작동하여 몸과 마음이 항 진되고 매사에 전투적으로 임하게 된다. 이로 인해 맥부(脈浮), 두항강통(頭項强通)이 나타나게 되는 것 이다. 이러한 경쟁심과 승부욕의 이면에는 사랑을 쟁 취하거나 사람들과 함께 하고픈 사랑 및 소속 욕구가 존재한다. 이러한 유형의 사람은 어떤 집단이나 가족 내에서 자신의 자리를 간절히 원하고 인간관계를 맺 는 것이 세상의 다른 무엇보다 중요하며, 나아가 외 로움, 배척, 친구의 부재, 불안정에서 비롯되는 고통 이 온통 내면을 지배하게 된다. ${ }^{16)}$

본 증례 보고의 환자는 알콜중독으로 폭력적이고 권위적인 아버지 밑에서 유년 시절을 보냈다. 19세 때 아버지가 사고로 다리를 절단하는 사건이 있었고 그 후 알콜중독이 더 심해지면서 수시로 폭력을 일삼 았다. 어머니는 신경질적이고 예민한 성격으로 말을 함부로 내뱉는 성향이었다. 아버지에 대한 공포와 폭 행에 대한 불안감을 느꼈다. 가족 내에서 소속감을 느낄 수 없었고 우울한 가정환경에서 성장했다. 지방 대를 졸업하고 신문사에 입사하였으나 무시하는 듯 한 주변의 시선 때문에 열등감을 느꼈고 인정받고 싶 은 마음에 승부욕, 경쟁심이 발동하여 다른 사람보다 무리하게 일을 하며 몸을 혹사시켰다. 다른 사람에게 인정 받기 위해 누구보다 잘해야 하고 반드시 성공해 야 한다는 생각 때문에 부담감을 느꼈고 실패에 대한 불안이 있었다.

환자를 태양병(太陽病)으로 진단 후 15 조를 선정했다. 15 조의 '기기상충자(其氣上衝者)' 는 숨이 막히고
기운이 위로 솟구쳐서 쓰러질 듯한 현상이 병의 원인 으로 작용하는 경우를 말한다. ${ }^{17)}$

상한론(傷寒論) 15 조의 '기상충(氣上衝)'에 관한 제 가의 이론에 대해 고찰한 이 ${ }^{18)}$ 등에 다르면 '기상충 (氣上衝)'은 크게 '기(氣)'와 '상충(上衝)'으로 나누어 해석할 수 있는데, 역대 의가들은 '기(氣)'를 정기(正 氣), 외감사기(外感邪氣), 태양경기(太陽經氣) 그리고 장간기체(腸間氣滯)로 역상(逆上)하는 기운이라 설명 하였고, '상충(上衝)'은 외향성(外向性)을 띄고 발생 하는 일련의 증상군의 내포, 혹은 비(㾂)나 결(結)과 같은 단일 증상 또는 두항강통(頭項强通)이라 설명하 였다.

'기상충(氣上衝)'을 상한론(傷寒論)이 저술된 중국 후한(後漢) 시대의 고문자로 해석해보면 한나라 때에 는 쌀 미(米)를 자소로하는 문자 기(氣)가 없었다. 고 대의 글꼴은 기(气)로 설문해자에서는 구름이 흐르는 모습을 그린 상형문이라고 풀고 있다. 즉 바람 등 눈 에 보이지는 않으나 움직이고 있는 기운(에너지)을 묘사한 글자이다. 후대문헌에서는 호흡의 들고 나는 숨을 의미하기도 하며 몸 전체의 기운을 나타내기도 한다. 상(上)은 ‘위로 오르다’라는 뜻의 동사이다. 충 (衝)은 사거리를 위에서 내려다 본 형태의 갈 행(行) 가운데 무거울 중(重)이 들어있다. 사거리는 적극적 인 행동을 상징하며 여기에 무게감 있는 행동을 더해 의미를 강조했다. 강하고 급격한 힘의 분출을 의미한 다. ${ }^{19)}$ 즉 '기상충(氣上衝)'은 '눈에 보이지는 않으나 움직이고 있는 몸 전체의 기운, 또는 호흡의 들고 나 눈 숨이 강하고 급격하게 위로 분출되어 오르는 현 상'으로 해석할 수 있다. 본 증례에서는 '기상충(氣上 衝)'을 현대의 공황장애에서 보여지는 심계항진, 호 흡곤란, 가슴답답함, 쓰러질 것 같은 증상과 유사하 다는 가설을 세우고 계지탕(桂枝湯)을 투여하였다.

이러한 판단 하에 치료의 목표를 첫째 인체의 항 상성을 회복시켜 외부의 스트레스에 의해 깨어진 균 형을 바로 잡는 것, 둘째 질병이 오게 되는 원인과 내면의 동기를 인지시키는 것, 셋째 불안에 대한 내 
성을 높여 불안을 제거의 대상이 아닌 충분히 다루어 낼 수 있는 현상으로 인식하게 하는 것으로 잡고 치 료를 진행하였다.

상담을 통해 유년 시절에 충족되지 못한 사랑과 소속 욕구를 채우기 위해 과잉된 활동을 하게 되고 성공에 대한 부담과 실패에 대한 불안으로 공황장애 가 오는 것을 인지시켰다.

과로와 스트레스, 과음 후에 공황발작이 오는 것을 볼 때 적절한 휴식을 취하고 음주 대신 산책과 명상 을 통해 건전하게 스트레스를 해소하고 심신을 이완 할 것을 권유하였다.

약 25 주 동안 치료 한 후 실시한 동일 설문 검사에 서 BAI 감소(49->16), 공황발작 빈도와 강도, 불안 의 강도, 피로감, 두항강통(頭項强痛)이 모두 감소하 였고, 수면의 질이 개선되었다.

공황장애는 불안장애의 범주로 극심한 불안을 주 증상으로 하기 때문에 불안의 인지적, 정서적, 신체 적 영역을 포함하는 여러 가지 불안 증상의 정도를 측정하기 위해 $\mathrm{BAI}$ 를 평가도구로 사용하였으나, $\mathrm{BAI}$ 를 제외한 다면적 인성검사(MMPI), 간이정신진 단검사(SCL-90R), 상태-특성 불안척도(STAT) 등 정 신 증상을 평가하는 다른 척도를 시행하지 못한 점은 개선할 점이다.

본 증례는 1 례로서 통계적인 검정을 거치지 못하 였으나 그럼에도 불구하고 몸을 무리하게 사용하고 과잉된 활동을 하여 공황장애가 발생한 환자를 변병 진단체계(辨病診斷體系)에 근거하여 태양병(太陽病)으 로 진단하고, 15 조문의 기상충(氣上衝)을 공황장애와 연결하여 다른 치료 없이 계지탕 원방(桂枝湯 元方) 만을 투여하여 호전시킨 점에서 의의가 있다고 할 수 있겠다. 추후 상한론 변병진단체계(傷寒論 辨病診斷 體系)로 신경정신과 질환을 치료하는 다양한 연구에 사용될 기초자료로서의 역할을 기대한다.

\section{요 약}

본 증례보고에서는 과로 후 공황장애가 온 44세 남성 환자를 상한론 변병진단체계(傷寒論 辨病診斷體 系)에 입각하여 태양병(太陽病)으로 진단하고 15 조문 의 계지탕(桂枝湯)을 약 6개월 동안 투여한 결과 주 소증인 심계항진, 가슴답답함, 기역(氣逆), 호흡곤란 을 포함한 제반 증상들이 호전되는 치료적 효과를 확 인할 수 있었다.

\section{참고문헌}

1. Korean NeuroPsychiatric Assoclation. Textbook of neuropsychiatry . 2nd rev. ed. Seoul:Joongang moonhwasa. 2005:204,221.

2. The Textbook Compilation Committee of Neuro-psychiatry of Oriental Medical Schools in Nation. Revised Edition. The Neuropsychiatry of Oriental Medicine. Seoul:Jipmoondang. 2011: 페이지

3. Hwnag UW, Kim JH. Oriental Neuropsychiatry. Seoul:modern medical books. 1987:601.

4. Kim JH, Seok SH, Koo BS, Kim GW.A Case Report of Panic Disorder with Agoraphobia; Focusing on Observation from Recent Onset . Journal of korean neuropsychiatric association . 2008;19(2):251-63.

5. Suh HU, Hwnag EY, Jung SY, Kim JW. A Case of a Panic Disorder(with Agoraphobia) Patient Improved by Herbal Extracts Gyejigayonggolmoryo-tang (Guizhijialonggumuli-tang) and Jakyakgamcho-tang(Shaoyaogancao-tang). Journal of korean neuropsychiatric association. 2010;21(4):207-18.

6. Roh YB, Yun SM, Joh ES. Case Reports and Studies on the Functional Process of Panic 
Disorder, treated with Ling-Gui-Gan-Zao-Tang. Journal of Korean Medical Association of Clinical Sanghan-Geumgwe. 2012;4(1):1-12.

7. YooK SP, Kim JS. Clinical research of Korean edition Beck Anxiety Inventory: Comparison between patients and non-patients. Korean Journal of psychology. 96 Workshop Presentation file. 1996:41-9.

8. American Psychiatric Association. Diagnostic and Statistical Manual of Mental Disorders, Fourth Edition. Seoul:Hana medical publishing. 1995:514-26.

9. Asmundson GJ, Taylor S, A J Smits J. Panic disorder and agoraphobia: an overview and commentary on DSM-5 changes. Depress Anxiety. 2014;31(6):480-6.

10. Jung IC, Lee SR. The Clinical Analysis on 19 Cases of Anxiety Disorder. Journal of korean neuropsychiatric association. 1998;9(2):161-9.

11. Lee SW, Lee YJ, Yoo SW, Lee RD, Park SJ. Case Series of Panic Disorder Patients Treated by Oriental Medical Treatments and EFT . Journal of korean neuropsychiatric association. 2014;25(1):13-28.

12. Park KM, Choi SH. The comparative study of Sanghanron and HwangHenaegyeong through historical study on Gangpyung Sanghanron. Journal of Korean Medical Classics. 1996;9: 265-301.

13. Lee SJ, Lim JE. A diagnostic system and clinical application based on <Shanghanlun> six meridian patterns and provisions. Seoul: Kmediacs publishing house.2013.

14. Lim JE, Lee SJ. A case report form based on Shanghanlun six clinical patterns and provisions. Journal of Korean Medical Association of Clinical Sanghan-Geumgwe.2013:5(1):1-17.

15. Lee SJ, Heo J. A case report of tinnitus treated by CyeJigagalgeun-tang. Journal of Korean Medical Association of Clinical Sanghan -Geumgwe. 2015:7(1):15-20.

16. Abraham HM. Motivation and Personality. Gyeonggi-do:book21.2009:92,93.

17. Roh YB. Clinical Shanghanlun; The application of Shanghanlun-psychopathy and intractable disease. Seoul:badabooks. 2020:129,130.

18. Lee SJ, Kim YM. A study of 'Ji-Qi-Shang-Chong (其氣上衝)' and Gui-Zhi-Tang(桂枝湯)in Shang -han-lun. Journal of The Korean Medicine Society For The Herbal Formula Study. 2012:20(2):165-176.

19. Kim KI. Shanghanlun; Chinese Paleographical translation. Seoul:badabooks. 2015:87,88.

\section{ORCID}

노영범 https://orcid.org/0000-0002-8756-4727

김지영 https//orcid.org/0000-0002-4269-7358 